\title{
Spinoza and the Icosahedron
}

\section{Eugene A. Katz}

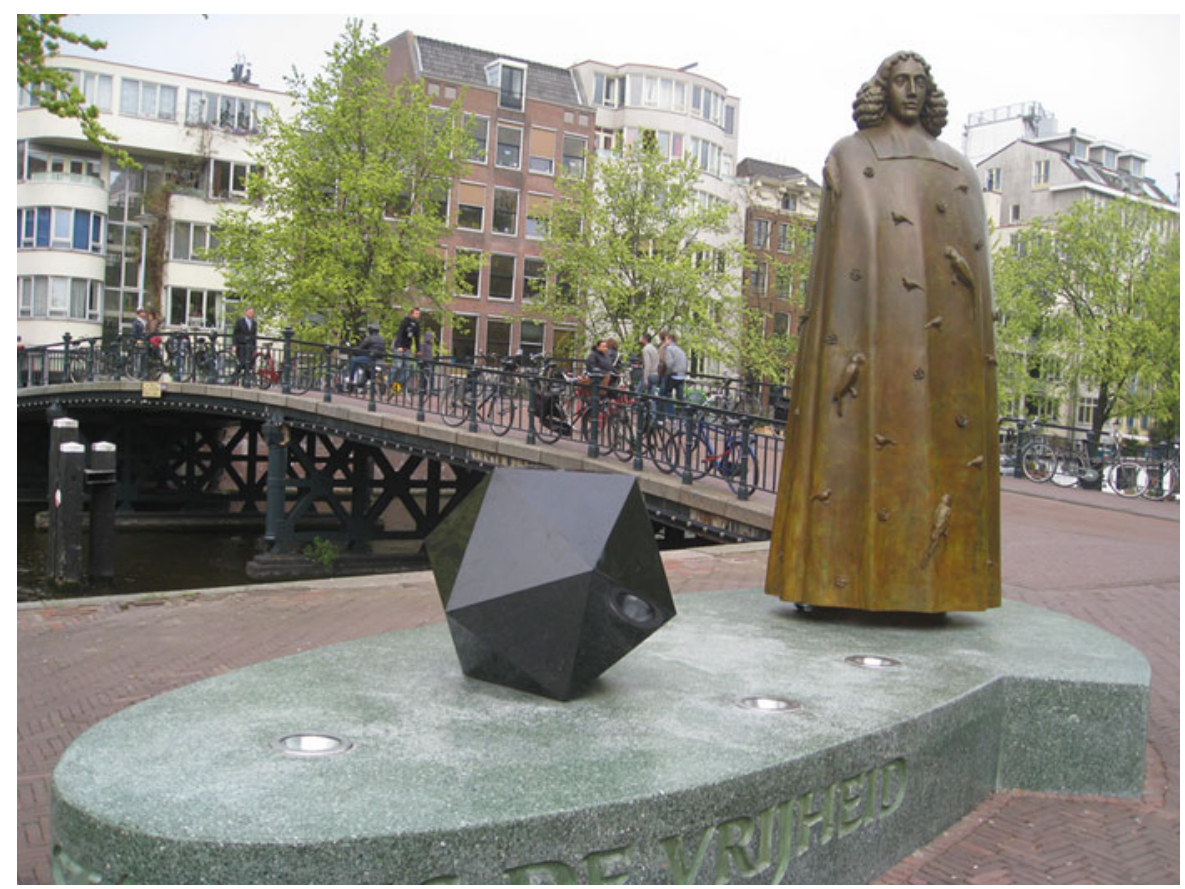

This monument to Baruch Spinoza by the sculptor Nicolas Dings was unveiled in Amsterdam in 2008. The Platonic icosahedron represents the classical "element" water and symbolizes the Universe polished by human thinking. It also alludes to Spinoza's job as a lens polisher. Photo by E.A. Katz. 